\title{
Cloud Class dan Cloud Meeting; Model Pembelajaran Pascasarjana dan Meeting Pimpinan
}

\section{Cloud Class and Cloud Meeting; Postgraduate Learning Model and The Leaders Meeting}

\author{
Eka Prihatin*, Danny Meirawan, Ratu Dintha IZFS, \& Enjang Alinurdin \\ Universitas Pendidikan Indonesia, Bandung, Jawa Barat, Indonesia \\ ekaprihatin@upi.edu*
}

Naskah diterima tanggal 25/11/2020, direvisi akhir tanggal 27/12/2020, disetujui tanggal 31/12/2020

\begin{abstract}
Abstrak
Memilih untuk melanjutkan sekolah ke pascasarjana menjadi keputusan yang tidak mudah, dimana banyak faktor yang harus dipertimbangkan, yang utama dan terpenting adalah masalah biaya dan alokasi waktu. Kenapa demikian karena hampir $80 \%$ mahasiswa pascasarjana sudah menjadi pegawai di berbagai instansi, dan pasarannya mencakup seluruh nusantara, sehingga jika memilih sekolah maka banyak kegiatan yang harus ditinggalkan. Salah satu alternative pemecahan masalah ini untuk win-win solution adalah dengan mulai membangung cloud class, dimana dengan program ini, maka efektifitas dan efisiensi sumber daya yang digunakan untuk menlajutkan sekolah dapat ditekan seminimal mungkin. Demikian juga karena UPI memiliki beberapa UPI Kampus Daerah, maka ketika diperlukan untuk rapat pimpinan yang mengharuskan semua pimpinan atau undangan dalam kegiatan apapun memerlukan sumber dana yang tidak sedikit, demikian juga waktu karena jarak yang jauh, solusi dari hal tersebut dengan menggunakan cloud meeting sehingga sumber daya yang dikeluarkan untuk mengikuti rapat ditekan seminimal mungkin. Maka dengan demikian penelitian ini sangat tepat untuk dilaksanakan.
\end{abstract}

Kata kunci: Cloud Class; Cloud Meeting; Efektif; Efisien; Sumber Daya.

\begin{abstract}
Choosing to continue school to graduate school is not an easy decision, where many factors must be considered, the main and most important is the problem of cost and time allocation. Why is that because almost $80 \%$ of postgraduate students have become employees in various agencies, and the market covers the entire archipelago, so if you choose a school, you have to leave a lot of activities. One alternative solution to this problem for a win-win solution is to start building a cloud class, where with this program, the effectiveness and efficiency of the resources used to continue the school can be minimized. Likewise, because UPI has several Regional Campus UPIs, when it is necessary for a leadership meeting that requires all leaders or invitations in any activity it requires a large amount of funding, as well as time due to long distances, the solution to this is by using a cloud meeting so that the source the power released to attend the meeting is kept to a minimum. So thus this research is very appropriate to be carried out.
\end{abstract}

Keywords: Cloud Class; Cloud Meeting; Effective; Efficient; Resources. 


\section{PENDAHULUAN}

Revolusi industry 4.0 merupakan trend dunia yang ditandai dengan sistem otomasi. Sistem ini menjadi trend yang diaplikasikan hampir disemua aspek kegiatan kehidupan. (Alaloul et al., 2018; Demangeon et al., 1925; Nagy et al., 2018; Rojko, 2017; Zheng et al., 2018) pengaruh berkembangnya internet forlof things yang mendorong pengembangan big data dan artificial intelligence (Allam \& Dhunny, 2019; China State Council \& Foundation for Law and International Affairs, 2017; OECD, 2019; Organisation for Economic Co-operation and Development, 2016; Osuwa et al., 2018)

Sejarah dari revolusi industry ini secara sederhana dimulai dengan revolusi industry 1.0 yaitu steam angine dengan ditemukannya menis uap, yang kemudian berkembangan menjadi revolusi industry 2.0 dengan ditemukannya listrik; dilanjutkan dengan revolusi industry 3.0 yang ditandai dengan computer dan berkembang pesat menjadi revolusi industry 4.0 yang dipenuhi dengan automation. Dampak dari RI 4,0 ini meluas dengan cepat pada setiap kegiatan dalam kehidupan, tidak terlepas dengan dunia pendidikan.

Dalam manajemen pendidikan maka automation menguasai layanan pendidikan sehingga memanjakan pelanggannya dengan memberikan kemudahan dan kecepatan dalam layanan akademik. Dalam layanan proses belajar mengajar memunculan adangan e-learning, distance learning, massive open online couse (MOOCs) yang menjadi pilihan remaja dunia dalam proses pembelajaran andragogi.

Trend pembelajaran IR4.0 dengan berlombanya universitas terkemuka di seluruh dunia untuk membuka pembelajaran dengan online sistem. Dengan memanfaatkan internet of things yang menjadi ciri dari IR 4.0, maka dalam proses pembelajaran pun di desain dengan memaksimalkan manfaat internet of things. Sebutkan MOOCs yaitu massive open online course yaitu metode pembelajaran jarak jauh yang berskala besar bisa diakses oleh seluruh dunia (Baturay, 2015).

MOOCs menjadi favorit dikalangan anak seluruh dunia (Baturay, 2015; Brown, 2018; Jurnal Penelitian Pendidikan
Franco et al., 2014; Holstein \& Cohen, 2016; OpenupEd, 2015; Zhong et al., 2016), karena pertama. sifatnya yang gratis; kedua, menyediakan sartifikat; dan ketiga, pilihan jurusannya yang banyak. Di beberapa negara banyak generasi muda yang mengikuti pembelajaran untuk beberapa bidang studi sesuai dengan tujuan karir mereka, sehingga dikarenakan gratis maka animo yang terjadi adalah penurunan mahasiswa dibeberapa universitas bereputasi di seluruh dunia sebagai dampak perkembangan MOOCs.

MOOC adalah kursus yang dirancang untuk sejumlah besar peserta, yang dapat diakses oleh siapa saja, di mana saja selama mereka memiliki koneksi internet, terbuka untuk semua orang tanpa masuk kualifikasi, dan menawarkan pengalaman kursus penuh / lengkap online secara gratis

Model pembelajaran MOOCs ini memberikan inspirasi kepada penulis untuk mengawinkan model MOOCs ini dengan model pembelajaran konvensional. Dimana konsep cloud class ini adalah pembelajaran secara online akan tetapi seperti kita di dalam kelas. Konsepnya seperti videocall/ teleconference hanya saja terkonek secara klasical. Jika satu kelas itu terdiri dari 30 orang, maka dalam layer dosen dan laptop mahasiswa akan hadir 30 layar juga yang menunjukkan mahasiswa yang hadir, hal ini memungkinkan terjadi komunikasi interaksif antara semuanya, persis sama dengan perkuliahan konvensional hanya saja mahasiswanya tersebar diseluruh daerah/ negara.

Cloud class ini bisa diikuti oleh mahasiswa dari seluruh dunia dengan media videocall/ teleconference secara klasikal. Perbedaan dengan konsep MOOCs adalah proses pembelajarannya dimana komunikasi hanya sepihak diikuti dengan tanya jawab dalam media terpisah, sedangkan cloud class multi way, persis seperti proses pembelajaran dikelas akan tetapi dilakukan secara online, jadi terjadi komunickasi interaktif secara acak keseluruh peserta/ mahasiswa.

Cloud class akan menciptakan proses pembelajaran dengan interaktif yang optimal antara dosen dan mahasiswa maupun antar mahasiswa di berbagai daerah. Analisis daric laud class ini adalah (1) menekan pembiayaan pendidikan (kost, transfortasi); (2) tidak 
membutuhkan ruang yang luas dan banyak; (3) kehadiran peserta didik terkontrol; (4) pendidikan dapat diakses oleh mahasiswa dari berbagai daerah; (5) harga terjangkau oleh masyarakat sehingga akan mendorong minat calon mahasiswa; (6) menekan kebutuhan tenaga pendidik dan kependidikan; (7) sarana prasarana pendidikan yang dibutuhkan hanya peralatan yang menunjang teleconfren saja.

Banyak riset yang mengkaji MOOCs diantaranya adalah (Olazabalaga, Garrido, \& Ruiz, 2016) namun dapat dilihat pengembangan yang dilakukan dengan cloud class pada tabel 1 .

Tabel 1. Perbedaan MOOCs dan Cloud Class

\begin{tabular}{|c|c|c|c|}
\hline \multicolumn{2}{|c|}{ MOOCs (OpenupEd, 2015) } & \multicolumn{2}{|c|}{ Cloud class (Peneliti, 2019) } \\
\hline \multicolumn{4}{|l|}{ Massive } \\
\hline \multirow[t]{2}{*}{$\begin{array}{l}\text { Kursus online } \\
\text { yang dirancang untuk } \\
\text { sejumlah besar } \\
\text { peserta }\end{array}$} & $\begin{array}{l}\text { Jumlah peserta lebih besar dari } \\
\text { yang bisa diajarkan di ruang } \\
\text { kelas kampus 'normal' /situasi } \\
\text { kuliah (> 150) }\end{array}$ & $\begin{array}{l}\text { Perkuliahan secara } \\
\text { online (S1, S2 dan S3) } \\
\text { dirancang untuk jumlah } \\
\text { mahasiswa maks } 50 \\
\text { orang }\end{array}$ & $\begin{array}{l}\text { Jumlah peserta sesuai } \\
\text { dengan kelas kampus normal }\end{array}$ \\
\hline & $\begin{array}{l}\text { Kursus (model pedagogis) } \\
\text { sedemikian rupa sehingga } \\
\text { upaya semua layanan } \\
\text { (termasuk staf akademik } \\
\text { tentang bimbingan belajar, tes, } \\
\text { dll.) Tidak meningkat secara } \\
\text { signifikan karena jumlah } \\
\text { peserta meningkat }\end{array}$ & & $\begin{array}{l}\text { Perkuliahan (model } \\
\text { pedagogis) seperti } \\
\text { perkuliahan konvensional, } \\
\text { semua bentuk layanan } \\
\text { akademik sama dengan } \\
\text { kampus pada umumnya } \\
\text { hanya dilakukan secara } \\
\text { online }\end{array}$ \\
\hline \multicolumn{4}{|l|}{ Open } \\
\hline \multirow[t]{4}{*}{$\begin{array}{l}\text { Kursus dapat diakses } \\
\text { oleh (hampir) siapa } \\
\text { saja di mana saja } \\
\text { Sslama mereka } \\
\text { memiliki koneksi } \\
\text { internet }\end{array}$} & $\begin{array}{l}\text { Kursus dapat diakses oleh } \\
\text { (hampir) semua orang tanpa } \\
\text { batasan. } \\
\text { - Setidaknya konten kursus } \\
\text { selalu dapat diakses } \\
\text { - Kursus dapat diakses di } \\
\text { mana saja selama mereka } \\
\text { memiliki koneksi internet }\end{array}$ & $\begin{array}{l}\text { Perkuliahan dapat } \\
\text { diakses menurut } \\
\text { persyaratan tertentu, } \\
\text { dimana saja dan harus } \\
\text { memiliki koneksi } \\
\text { internet }\end{array}$ & $\begin{array}{l}\text { Perkuliahan hanya daapat } \\
\text { diakses oleh mereka yang } \\
\text { lolos seleksi masuk PT, } \\
\text { menurut jurusan yang dipilih } \\
\text { dan dapat diakses dimana } \\
\text { saja dan harus memiliki } \\
\text { koneksi internet }\end{array}$ \\
\hline & $\begin{array}{l}\text { Terbuka seperti dalam } \\
\text { kebebasan tempat, kecepatan } \\
\text { dan waktu }\end{array}$ & & $\begin{array}{l}\text { Terbuka dalam kebebasan } \\
\text { tempat akan tetapi dalam } \\
\text { waktu yang sama sesuai } \\
\text { tempat PT }\end{array}$ \\
\hline & $\begin{array}{l}\text { Terbuka untuk semua orang } \\
\text { tanpa entri kualifikasi. }\end{array}$ & & $\begin{array}{l}\text { Ada kualifikasi sesuai } \\
\text { persyaratan PT yaitu tamat } \\
\text { SMA }\end{array}$ \\
\hline & Kursus bersifat gratis & & $\begin{array}{l}\text { Ada kewajiban untuk } \\
\text { membayar biaya / semester } \\
\text { yang telah ditetapkan }\end{array}$ \\
\hline \multicolumn{4}{|l|}{ On line } \\
\hline \multirow[t]{2}{*}{$\begin{array}{l}\text { Kursus online } \\
\text { lengkap }\end{array}$} & $\begin{array}{l}\text { Semua aspek disampaikan } \\
\text { secara online }\end{array}$ & $\begin{array}{l}\text { Perkuliahan dilakukan } \\
\text { secara teleconference } \\
\text { klasikal }\end{array}$ & $\begin{array}{l}\text { Semua mata kuliah diajarkan } \\
\text { secara teleconference } \\
\text { klasikal }\end{array}$ \\
\hline & $\begin{array}{l}\text { Total waktu belajar MOOCS } \\
\text { minimal } 1 \text { ECTS (biasanya } \\
\text { antara 1-4 ECTS) }\end{array}$ & & $\begin{array}{l}\text { Total belajar mahasiswa } \\
\text { yang biasanya/ semester } \\
\text { maka dalam cloudclass } \\
\text { menjadi catur wulan ( } 4 \\
\text { bulan). Dengan demikian } \\
\text { untuk menyelesaikan } \mathrm{S} 1 \\
\text { yang biasanya } 8 \text { semester } \\
\text { maka akan dilakukan } 8 \\
\text { caturwulan jadi } 32 \text { bulan } \\
\text { atau } 2 \text { tahun } 8 \text { bulan. }\end{array}$ \\
\hline
\end{tabular}




\begin{tabular}{|c|c|c|c|}
\hline Konten pendidikan & $\begin{array}{l}\text { Konten pendidikan mencakup } \\
\text { video-audio-teks-game } \\
\text { (termasuk stimulasi)- media } \\
\text { sosial- animasi }\end{array}$ & Konten pendidikan & $\begin{array}{l}\text { Pembelajaran dilakukan } \\
\text { melalui teleconference yang } \\
\text { bersifat klasikal }\end{array}$ \\
\hline $\begin{array}{l}\text { Fasilitasi interaksi } \\
\text { antar teman sebaya } \\
\text { (termasuk dengan staf } \\
\text { akademik) }\end{array}$ & $\begin{array}{l}\text { Berinteraksi melalui saluran } \\
\text { media sosial, forum, blog atau } \\
\text { RSS pembaca untuk } \\
\text { membangun komunitas } \\
\text { pembelajar }\end{array}$ & & $\begin{array}{l}\text { Diskusi didalam kelas bai } \\
\text { kantar dosen dan mahasiswa, } \\
\text { juga antar teman sebaya } \\
\text { selama masa jam kuliah } \\
\text { maka dilakukan secara } \\
\text { teleconference. Akan tetapi } \\
\text { apabila akan berinteraksi } \\
\text { sesudah perkuliahan selesai } \\
\text { itu bisa dilakukan sesuai } \\
\text { dengan pilihan mahasiswa }\end{array}$ \\
\hline $\begin{array}{l}\text { Kegiatan/tugas, tes } \\
\text { termasuk umpan } \\
\text { balik }\end{array}$ & $\begin{array}{l}\text { Peserta diberikan beberapa } \\
\text { mekanisme umpan balik, dari } \\
\text { teman sebaya maupun staf } \\
\text { akademik }\end{array}$ & & $\begin{array}{l}\text { Didalam perkuliahan ada } \\
\text { diskusi dan tanya jawab } \\
\text { serta tugas maupun test } \\
\text { dilakukan dengan } \\
\text { kesepakatan dosen dan } \\
\text { mahasiswa }\end{array}$ \\
\hline $\begin{array}{l}\text { Termasuk pendidikan } \\
\text { nonformal }\end{array}$ & $\begin{array}{l}\text { Selalu menyertakan sertifikat/ } \\
\text { lencana }\end{array}$ & $\begin{array}{l}\text { Temasuk pendidikan } \\
\text { formal }\end{array}$ & $\begin{array}{l}\text { Jika sudah mengikuti } 8 \\
\text { caturwulan maka mahasiswa } \\
\text { akan mendapatkan ijazah S1 } \\
\text { ditambah dengan sertifikat } \\
\text { untuk mata kuliah yang } \\
\text { bersifat skill }\end{array}$ \\
\hline
\end{tabular}

Dengan demikian bahwa Cloud class merupakan pengembangan dan penyempurnaan dari model pembelajaran MOOCS yang akan diaplikasikan untuk proses pembelajaran andragogi yaitu pada Pendidikan Tinggi program sarjana, magister dan doctor. Cloud class dalam penelitian ini dikhususkan untuk mahasiswa program pascasarjana dengan asumsi bahwa:

1. Mahasiswa pascasarjana berasala dari seluruh nusantara

2. Dalam rombel antara $3<$ dan $>30$ mahasiswa

3. $80 \%$ mahasiswa sudah tercatat sebagai pegawai di berbagai instansi

Sehingga metode cloud class ini merupakan alternative yang paling tepat untuk mengatasi permasalahan dan hambatan yang biasanya dimiliki oleh mahasiswa pascasarjana.

Cloud class ini akan menekan biaya dan waktu yang dibutuhkan oleh mahasiswa pascasarjana, penekanan pada biaya, karena dengan cloud class ini maka proses pembelajaran bisa diakses dimana saja menyesuaikan dengan jadwal pelajaran dengan waktu bagian barat (UPI). Dampaknya adalah:
1. Mahasiswa tidak usah mengeluarkan dana untuk biaya transfortasi atau biaya kost

2. Mahasiswa meminta ijin sekolah hanya untuk waktu tertentu sesuai dengan jadwal sehingga tupoksi tetap terlaksana

Kelemahannya adalah, karena cloud class ini sangat tergantung dengan teknologi dan akses internet maka quota internet harus tersedia.

Demikian juga dengan cloud meeting, hal ini akan memudahkan komunikasi antara UPI Kampus Bumi Siliwangi dengan UPI kampus Cibiru, Sumedang, Tasikmalaya, Purwakarta dan Serang. Dimana jika ada kegiatan atau rapat apapun dapat dilaksanakan melalui cloud meeting, dengan demikian undangan yang harus datang dari berbagai kampus daerah dengan dana dan waktu yang sangat banyak akan ditekan melalui cloud meeting. Dampak nyata adalah UPI dapat mengurangi alokasi dana untuk transfortasi, dan layanan akademik di UPI Kampus Daerah dapat dilaksanakan secara lancar.

Sehingga model cloud class untuk pembelajaran mahasiswa pasca sarjana dan model meeting class untuk rapat dan kegiatan di lingkungan UPI sangat tepat menjadi alternative solusi hambatan yang terjadi pada masa kini. 
Administrasi pendidikan di perguruan tinggi tidak berdiri sendiri akan tetapi sangat dipengaruhi oleh trend global. Dampak Revolusi Industri 4.0 terhadap pendidikan adalah (1) perubahan learning needs; (2) profil baru peserta didik; (3) virtualization proses pendidikan; (4) online modes of learning and teaching; (5) digitalization of management; (6) perubahan persyaratan, prosedur dan metode kerja. Salah satu strategi untuk menjawab dampak tersebut adalah cloud class yang dipakai dalam proses pembelajaran.

Cloud class dan cloud meeting itu sendiri merupakan pengembangan dari model pembelajaran MOOCs yang menjadi trend di 194 negara yang ada di dunia. MOOCs itu sendiri adalah massive open online course, merupakan layanan pendidikan gratis yang dapat diakses oleh seluruh warga dunia.(Baturay, 2015; Brown, 2018; Franco Yanez et al., 2014; Holstein \& Cohen, 2016; Olazabalaga et al., 2016; OpenupEd, 2015; Zhong et al., 2016).

Ciri dari MOOCs adalah pembelajaran bersifat online; (2) banyaknya peserta didiknya tidak dibatasi; (3) tidak ada persyaratan menjadi peserta didik kecuali memiliki koneksi internet; (4) merupakan pendidikan nonformal; (5) pesera didik boleh memilih lebih dari satu kursus; (6) akhir pendidikan mendapatkan sertifikat; (7) tidak dipungut biaya pendidikan (OpenupEd, 2015).

MOOCs itu sendiri merupakan salah satu model pendidikan sesuai dengan IR 4.0, sehingga model itu menjadi inspirasi untuk dikembangkan lebih ke pendidikan Indonesia, sehingga rasa pedagogiknya masih tetap kental dengan model pembelajaran yang canggih. Harapannya akan memberikan manfaat yang tinggi bagi berbagai pihak.

\section{METODE PENELITIAN}

Analisis dari kajian tersebut menjadi penyempurnaan dan pengembangan model Cloud Class dan Cloud meeting yang menjadi fokus kajian penelitian ini. Cloud class dan Cloud meeting akan disajikan menjadi desain model yang layak untuk diujicoba di UPI sebagai Universitas yang menjadi pelopor dan rujukan bagi perguruan tinggi lainnya.

\section{HASIL DAN PEMBAHASAN}

\subsection{Hasil}

Data dan informasi sebagai temuan dilapangan secara keseluruhan menunjukkan bahwa $63 \%$ responden menyatakan bahwa pembelajaran secara daring kurang efektif dan $37 \%$ responden menyatakan cukup efektif dan bisa diikuti, dengan rincian sebagai berikut:

Pertanyaan 1 berkaitan dengan bagaimana pandangannya tentang pembelajaran daring yang dilaksanakan pada masa covid-19, semua responden menyatakan bahwa model pembelajaran ini kurang efektif, dengan berbagai alasan diantaranya adalah (1) kurang maksimal dalam mencerna dan memahami materi pembelajaran; (2) banyak kendala dalam akses terutama di daerah pedesaan; (3) Pembelajaran daring dirasa sangat membosankan, dan penyampaian materinyapun seperti kurang maksimal karena tidak ada interaksi secara langsung dengan dosen; (3) Pembelajaran daring dari sebelumnya menggunakan absensi manual sekarang sudah ada perkembangan dengan melukan absen online melalui google form. Dan pastinya Selalu ada kendala dalam pelaksanaannya jaringan dan kuota; (4) Tingkat keberhasilan pembelajaran daring dipengaruhi oleh faktor-faktor utamanya, yaitu alat IT dan jaringan internet; (5) Jika pembelajaran materi lumayan mengerti jika praktik tidak mengerti; (6) lebih mengeluarkan banyak biaya, dan uang fasilitas tetap harus dibayar meski fasilitas di kampus belum bisa dinikmati di masa pandemic.

Sedangkan responden yang menyatakan bahwa model ini cukup efektif dengan pendapat (1) Positifnya banyak pembelajaran berupa video sehingga bisa diulang...; (2) efektif jika kendala dalam hal ini internet stabil dan dari segi teknis dan tekhnologi nya; (3) ada tantangan besar dalam pelaksanaan model pembelajaran jarak jauh. Salah satunya, akademika belum terbiasa menggunakan sistem pembelajaran yang bersifat Daring; (4) solusi yang tepat untuk mencegah penyebaran COVID-19. Meski begitu, orang-orang belum terbiasa dengan sistem seperti ini sama halnya seperti saya yang belum terbiasa.

Pertanyan ke 2 berkaitan dengan hambatan yang ditemui dalam pembelajaran / pertemuan Jurnal Penelitian Pendidikan 
melalui daring, dalam hal ini responden diantaranya menyatakan (1) Kendala sinyal; (2) Penjelasan materi pembelajaran tidak sejelas ketika tatap muka; (3) Susahnya berdiskusi secara langsung dan jelas; (4) Bantuan dari pemerintah/kampus kurang tersalurkan sevara merta, sehingga masih banyak mahasiswa yg mengeluh karena harus mengeluarkan budget yg lebih besar utk kuota; (5) Tidak semua mahasiswa mempunyai gawai/laptop yg memadai utk mengakses pembelajaran daring"; (6) Kuota yang di butuhkan cukup besar; (7) belum menguasai cara mengganti backgroud khususnya pada acara2 webinar atau ujian yg hrus d selaraskan dengam ketentuan acara; (8) Sulit berinteraksi langsung bersama teman; (9) Server media PJJ UPI seperti Spot terkadang susah untuk masuk; (10) Terjadinya kesalah pahaman dalam menangkap materi dari PJJ yang diberikan Dosen (kurang efektif)"; (11) Kedekatan Secara emosional menjadi tidak kuat; (12) Kemampuan maksimal dan terbaik saya sebagai mahasiswa sepertinya menjadi kurang terlihat. Karena hubungan hanya melewati daring; (13) Miss komunikasi Lebih besar peluangnya terjadi antara dosen dengan mahasiswa"; (14) sumber beljar; (15) Untuk yang mata kuliah praktek kesulitan; (16) kurang leluasa selama pembelajaran

Untuk pertanyaan yang ke 3 berkaitan dengan keuntungan yang dirasakan dalam mengikuti pembelajaran/pertemuan secara daring adalah sebagai berikut: (1) Lebih santai; (2) Bisa di lakukan di rumah, bisa jg lebih mudah saat nugas tidak perlu repot ke kampus; (3) Menumbuhkan motivasi untuk belajar mengenai Teknologi informasi ; (4) Bisa sambil bekerja ; (5) Lebih santai ketika dosen dan mahasiswa berinteraksi; (6) Dapat diikuti dimana saja kita berada; (7) Dapat tatap muka bila menggunakan zoom atau google meet, mempercepat pengiriman tugas yang diberikan oleh guru, tidak membuat anak bosan dirumah ; (8) Tidak harus menggunakan pakaian bagus untuk ke kampus; (9) Webinar banyak yg digratiskan sehingga untuk mudah untuk menambah ilmu ; (10) dapat mem-push tenaga pendidik agar lebih kreatif dan inovatif dalam menghidupkan kelas online.. sehingga Jurnal Penelitian Pendidikan terlaksana ide-ide baru; (11) Masih mendapatkan materi pelajaran yang memadai ; (12) Tidak perlu pergi jauh untuk tatap muka; (13) Bisa memiki waktu banyak dirumah; (14) Kapanpun dan dimanapun; (15) Membantu mencegah penularan wabah covid 19; (16) Banyak materi secara digital seperti video, file ms.word, pdf, dll.. Yang dapat kita ulang kembali materinya; (17) Waktu dan tempat yang fleksible; (18) Merasa lebih aman seperti jaga jarak; (19) Pemaparan yang dibuat menjadi video dapat kita ulangi lagi; (20) Menambah pengalaman; (21) Lebih mudah; (22) Pendidikan Indonesia lebih maju, Waktu belajar lebih singkat dibandingkan tatap muka langsung; (23) mengetahui cara bagaimana ber interaksi secara jauh atau berjarak; (24) menyesuaikan jam belajar sesuai keinginan.

Selanjutnya pertanyaan ke 4 tentang metode daring seperti apa yang paling tepat digunakan, jawaban responden antara lain adalah (1) dengan zoom meeting, karena hal tersebut kami dapat melakukan tatap muka walaupun kadang terkendala sinyal yang tak stabil; (2) diberikan tugas yang sifatnya bahan kajian bersama; (3) Metode pembelajaran daring bisa dilakukan tidak hanya dg satu metode misalnya model pembelajaran web cource, web centric cource, atau web enhance cource; (4) Metode penugasan menggunakan google classroom; (5) Metode penugasan di Spot UPI, sebagai pelengkap; (6) Bisa menggunakan video pembelajaran, atau dengan teka teki silang dalam menyampaikan materi; (7) meeting room yang disediakan tepat waktu, jika terlambat maksimal 10 menit; (8) Tergantung cara dosen yg menyampaikan; (9) Sistem dengan metode yang mudah dipahami; (10) lebih baik tatap muka langsung tetapi tetap mematuhi protokol Kesehatan; (11) Video pembelajaran yang dapat disimpan, sehingga dapat diputar kembali dilain waktu; (12) upload video di youtube karena dengan menggunakan youtube dosen dapat menjelaskan dengan jelas tanpa ada suaranya yg putus putus seperti dilakukan di zoom atau aplikasi lainnya dan jika lupa dengan pembelajaranya kita bisa membuka lagi vidio tersebut (13) Agar lebih dapat dipahami dan dimengerti oleh mahasiswa/i khususnya daring, diharapkan para dosen membuat video pembelajaran sesuai dengan matkul masing456 
masing disertai dengan contoh soal (jika matkul nya hitungan). Setelah selesai membuat video tersebut dikirim kan link nya kepada mahasiswa/i diusahakan tidak besar ukuran video nya. Agar tidak menguras kuota dan bisa dibuka di hp. Adapun manfaat dari video pembelajaran tersebut bisa di pelajari berulang ulang kali oleh para mahasiswa/i.

Pertanyaan yang ke 5, tentang tanggapannyajika daring digunakan selamanya dalam pembelajaran/ pertemuan di upi, hanya $37 \%$ responden yang menyatakan setuju sedangkan $63 \%$ responden sepakat menyatakan tidak setuju dengan alasan (1) Karena belajar bukan tentang menerima materi pembelajaran, tapi kami mahasiswa membutuhkan diskusi dengan teman sejawat juga; (2) dalam pembelajaran value dari pembelajaran kurang tersampaikan; (3) pasca sarjana itu kan dalam 1 kelas mungkin sekitar 15 orang, mgkn masih bisa di maksimalkan secara offline dengan menerapkan protocol kesehatan, mengingat masa aktif kuliah hanya 2 tahun, Supaya memudahkan Selama proses penelitian; (4) Lebih mengasikan untuk pertemua d kmpus karena bisa saling bertukar informasi dan pemikiran saat mengerjakam tugas atau kuliah; (5) tidak akan terjadi interaksi antara SDM dalam proses pendidikan, yang merupakan bagian penting dalam mentransferkan proses pendidikan kepribadiannya (Role model); (6) lebih membosankan apabila belajar dari rumah, dan tugas pun jadi lebih banyak serta kurangnya interaksi sosial dan menjadikan mahasiswa malas; (7) banyak tertinggal ilmu2 yang seharusnya didapat, karena suatu kendala atau hambatan yang sudah dijelaskan di atas, dan jika hanya sekedar pertemuan secara virtual sangat kurang efektiv dan sering kali susah mencerna ilmu2 yang diberikan oleh dosen; (8) Tidak bisa karna bagaimana nasib mahasiswa teknik dan keperawanan yang mengharuskan adanya praktik; (9) pelajaran secara offline pun diperlukan agar gedung kampus berguna, para dosen setidaknya pernah bertemu langsung dengan para mahasiswa, dan mahasiswa terjaga silaturahminya dengan teman-temannya; (10) harus disertai dengan paket data gratis selamanya, dan bebas uang fasilitas kampus selamanya; (11) tdk dapat ruh sesungguhnya 457 dan pengalaman yang berharga jika selamanya daring; (12) Karena belum tentu juga para mahasiswa/i mengikuti pembelajaran daring secara serius dan belum tentu juga materi yang disampaikan kepada mahasiswa/i dapat dipahami dan dimengerti oleh semua mahasiswa/i. Berbeda dengan belajar secara langsung para mahasiswa/i dapat bertanya langsung kepada dosen jika belum mengerti; (13) karena dikhawatirkan ilmu yang didapat tidak tersampaikan ataupun tidak diterima secara maksimal. terlebih jika mata kuliah yang membutuhkan praktik secara langsung.

Pertanyaan 6 adalah tanggapannya jika daring dan luring digunakan bergantian dalam pembelajaran/ pertemuan di upi (kemukakan \% ideal antara luring dan daring), jawaban responden adalah sebagai berikut: (1) daring $60 \%$ dan luring 40\%; (2) $40 \%$ daring, $60 \%$ luring; (3) daring $70: 30$ luring; (4) $70 \%$ luring $30 \%$ daring; (5) Daring $=50 \%$, Luring $=50 \%$; (6) Selama ini pembelajaran online hanya sebagai konsep, sebagai perangkat teknis, belum sebagai cara berpikir, sebagai paradigma pembelajaran. Padahal, pembelajaran online bukan metode untuk mengubah belajar tatap muka dengan aplikasi digital, bukan pula membebani siswa dengan tugas yang bertumpuk setiap hari. Pembelajaran secara online harusnya mendorong siswa menjadi kreatif mengakses sebanyak mungkin sumber pengetahuan, menghasilkan karya, mengasah wawasan secara luas; (7) pertemuan secara daring tidak sedikit menimbulkan orang tua dan murid menjadi stress; (8) Mungkin untuk daring dalam satu Minggu itu dua hari saja; (9) Menurut saya, pembelajaran secara daring dan Kuring secara bergantian dinilai kurang efektif karena lebih banyak menghabiskan biaya dan waktu ; (9) daring $45 \%$ sedangkan luring mungkin bisa $55 \%$.

Pertanyaan terakhir yaitu ke 7 adalah kebutuhan apa yang paling urgensi agar daring di upi agar dapat menjadi sarana yang tepat bagi segala kegiatan baik pembelajaran/ pertemuan dan yang lainnya, jawaban responden adalah sebagai berikut: (1) Karena kendala setiap mahasiswa berbeda, sebaiknya UPI dapat mengatasi kendala dari tiap mahasiswa jika ingin diterapkan pembelajaran daring yang efektif; (2) memaksimalkan Jurnal Penelitian Pendidikan 
layanan kuliah dengan baik meskipun saat pandemi misal soal perpus digital, surat digital, bantuan kuota dan tentunya tatap muka daring; (3) Menyediakan setiap ruangan mendapatkan facesield, sedia tisu basah, tisu kering dan hand sanitizer; (4) Server Spot UPI nya dimaksimalkan dalam implementasinya; (4) Pemberian bantuan kuota internet yang merata kepada tiap mahasiswa, walaupun dengan nominal yang tidak besar; (5) Kuota internet gratis; (6) Mengurangi biaya semester; (7) Transparansi dalam informasi; (7) Mempermudah mahasiswa dalam hal informasi akademik sehingga mahasiswa dapat menyelesaikan studinya dengan tepat waktu dan tetap terjaga kualitasnya; (8) Membangun komunikasi antara dosen dan mahasiswa; (9) Protokol Kesehatan; (10 ) Sinyal yang kuat dan Alat Komunikasi yang memadai; (11) rapat dengan mahasiswa yang berasal dari luar kota; (12) Komputer dan jaringan internet yg mumpuni; (13) Kita harus berani melangkah untuk menjadikan pembelajaran online sebagai kesempatan mentransformasi pendidikan kita. Semua para dosen harus bisa mengajar jarak jauh yang notabene harus menggunakan teknologi; (14) E learning dll,; (15) Kesiapan materi atau modul yang diberikan dosen untuk bahan pembelajaran mahasiswa, dan pemberian fasilitas kuota bagi dosen dan mahasiswa ; (16) Para Dosen membuat video pembelajaran sesuai dengan matkul masing-masing yang ukuran video nya tidak terlalu besar dan linknya dibagikan kepada mahasiswa.

\subsection{Pembahasan}

Temuan dilapangan sangat menarik, meskipun $63 \%$ responden yang menyatakan keberatan akan tetapi hal tersebut dapat diatasi dengan memaksimalkan kebutuhan yang dianggap mampu mendukung dan memperlancar pembelajaran online. Seperti yang dikemukakan oleh berbagai peneliti seperti (Murphy, 2020) yang membantah bahwa pada masa covid seharusnya perguruan tinggi di non aktifkan karena permasalahan dengan penyebaran ,Murphy berpendapat pendidikan dapat dilaksanakan melalui e-learning dengan merujuk pada standar prosedur 458 kesehatan. Demikian juga dengan (Barnes et al., 2020) di Amerika Serikat dalam menghadapi Covid, Western Governors University (WGU) Menyusun daftar regulator dari semua negara bagian, relaxation of student teaching requirement, program disampaikan secara online, siswa menyelesaikan tugas dan proses belajar mengajar di traditional classrooms, paralelisme antara guru dan guru, guru dan siswa, siswa dan siswa, to evaluate whether the host school's 458 kesehatan was still meeting the needs of the student teacher and if not, then to shift the student teacher to a different placement that was more virtual-friendly. Sehingga penelitian ini memiliki perbedaan dengan menggali pendapat mahasiswa tentang metode pembelajaran yang dipakai pada masa covid 19.

Ternyata untuk mahasiswa UPI khususnya dan Mahasiswa di Indonesia pada umumnya, demikian juga mahasiswa di berbagai negara untuk jenjang pendidikan tinggi memerlukan penangan yang lebih teliti dan apik serta professional untuk menjadikan model pembelajaran cloud class ini sebagai metode terbaru untuk pembelajaran di perguruan tinggi. Seperti yang dikemukakan oleh (Sharfuddin, 2020) bahwa covid 19 mendorong dunia melakukan perubahan pada ekonomi, sosial, pendidikan dan 458esehatan dimana tidak ada yang keluar dari krisis ini tanpa kehilangan sesuatu. Bagaimana sesuatu yang baru akan mengancam strategi yang lama yang dianggap sebagai zona aman, namun dalam kenyataan hal tersebut wajar, karena sesuatu yang baru akan menjadi masa transisi yang dialami oleh siapapun, terlebih lagi dunia pendidikan adalah dunia yang sangat luas, memiliki tujuan pribadi yang berbeda, kastemernya heterogeny dari segi gender, usia, suku, jenjang pendidikan, kemampuan, kompetensi guru, kepemimpinan dan banyak lagi hal yang berbeda dalam mengelola pendidikan.

Dan ternyata selain pembelajaran online, ada banyak strategi yang bisa dipakai untuk meningkatkan kualitas (Heyang \& Martin, 2020) yaitu bagaimana kita membangun dan mempertahankan serta meningkatkan hubungan nasional maupun global melalui dialog untuk meningkatkan kualitas 458 
pemahaman program studi kita. Peluang tersebut dapat diantisipasi untuk menutupi kekurangan dengan pembelajaran online, sehingga permasalahan dan hambatan dari metode ini dapat teratasi dan sebaliknya memberi peluang bagi kita untuk mengeksekusinya menjadi inovasi yang dapat meningkatkan kepercayaan dari masyarakat, kastemer, user dan yang lainnya tentang kualifikasi dan kompetensi pendidikan.

Juga untuk keluhan masalah praktek yang menjadi kendala dengan model pembelajaran ini (Van De Heyde \& Siebrits, 2020) mengemukakan salah satu desain model laboratorium yang bisa digunakan pada masa pandemic ini tanpa mengurangi kualitas praktek secara offline.

Disinilah peran dosen dan dukungan institusi untuk menyulap permasalahan yang dihadapi menjadi peluang yang bisa dikembangkan yaitu dengan menciptakan inovasi baru berkatan dengan layanan akademik dan proses belajar mengajar termasuk strategi praktek yang menjadi kendala dan permasalahan yang dihadapi pada masa ini dapat teratasi tanpa mengurangi kualitas prakter itu sendiri.

Meskipun temuan dilapangan menunjukkan lebih banyak responden yang merasa bahwa cloud class dan cloud meeting tidak efektif, akan tetapi membuka respon yang sangat positif terhadap perubahan yaitu dengan menyiapkan sumber daya universitas untuk menghilangkan segala hambatan dan permasalahan yang menjadi konsekuensi dan dampak strategi pembelajaran baru ini. Tentu saja banyak ahli yang mengemukakan tentang bagaimana implementasi kebijakan baru akan menimbulkan golongan yang menerima, yang menolak dan yang netral (Gaffar, 2020).

Dengan demikian kesuksesan sebuah kebijakan akan tergantung dari bagaimana pemimpin menangani permasalahan yang terjadi pada implementasi kebijakan, dimana hambatan dan permasalahan dan dampak harus dikelola secara professional untuk diarahkan pada tujuan yang ditetapkan. Sehingga ada banyak property yang harus dimiliki oleh seorang eksecutor kebijakan, diantaranya adalah (1) memahami permasalahan; (2) professional; (3) transparansi; (4) empowering; (5) 459 accountability dan yang lainnya (Benoit Rihoux, 2006).

Keadaan yang demikian mendorong adanya perubahan dalam segala hal, dimulai dengan perubahan mindset untuk tetap melakukan pembelajaran, demikian juga organisasi dan institusi melalukan learning organization, dan akhirnya terjadi perubahan paradigma di masyarakat sebagai dampak dari learning society.

Perubahan akan menjadikan kita selalu bergerak dinamis, tentu saja konsekuensinya akan tinggi sekali dimana peran semua orang dalam menyelesaikan hambatan, masalah, tantangan juga tuntutan memerlukan strategi tersendiri yang unik dan berbeda dengan yang lainnya, yang menjadikan dunia ini akan lebih hidup.

\section{KESIMPULAN}

Covid 19 menjadi pemicu learning organization unruk merubah strategi layanan akademik diberbagai pendidikan baik formal maupun informal. Cloud class menjadi pilihan hamper semua perguruan tinggi agar pembelajaran tetap terlaksana. Dengan demikian hanya $63 \%$ responden yang menyatakan proses pembelajaran melalui daring itu tidak efektif dengan alasan serta hambatannya dan $37 \%$ yang menyatakan efektif akan tetapi harus disertadi dukungan fasilitas, dan meskipun strategi ini dirasakan tidak efektif dengan hambatan lebbih besar dari keuntungannya, namun layak untuk dicoba dilakukan dengan memperbaiki sarana dan prasarana serta kualitas mengajar harus lebih dioptimalkan.

Persepsi mahasiswa dalam menanggapi model pembelajaran cloud class ini, lebih banyak yang berpendapat kurang efektif sehingga harus di mixed antara luring dan daring dengan prosentase yang berbeda, namun tidak sedikit yang menyatakan jika di mixed maka membutuhkan dana yang lebih banyak karena ada biaya tranfortasi, kost dan makan yang selalu ditambah setiap dilakukan secara luring. Dan secara positif, data dan informasi ini dapat menjadi bahan evaluasi diri bagi institusi untuk menyelesaikan permasalahan umum yang dirasakan oleh mahasiswa dan dilakukan analisis terhadap solusi alternatif 
penyelesaiiannya, sekaligus menganalisis peluang yang ada di setiap permasalahan yang dimiliki mahasiswa untuk dieksekusi menjadi keunggulan perguruan tinggi agar tetap survive dalam setiap perubahan. 


\section{DAFTAR PUSTAKA}

Alaloul, W. S., Liew, M. S., Zawawi, N. A. W. A., \& Mohammed, B. S. (2018). Industry Revolution IR 4.0: Future Opportunities and Challenges in Construction Industry. MATEC Web of Conferences, 203, 1-7. https://doi.org/10.1051/matecconf/201820302010

Allam, Z., \& Dhunny, Z. A. (2019). On big data, artificial intelligence and smart cities. Cities, 89(January), 80-91. https://doi.org/10.1016/j.cities.2019.01.032

Demangeon, A., B., E. A., \& Low, E. F. (1925). The British Empire: A Study in Colonial Geography. The Geographical Journal, 66(4), 372. https://doi.org/10.2307/1782970

Barnes, R., Hall, R., Lowe, V., Pottinger, C., \& Popham, A. (2020). Lessons from an online teacher preparation Program: flexing work experience to meet student needs and regulators' requirements in the United States. Journal of Education for Teaching, 00(00), 1-8. https://doi.org/10.1080/02607476.2020.1802203

Baturay, M. H. (2015). An Overview of the World of MOOCs. Procedia - Social and Behavioral Sciences, 174, 427-433. https://doi.org/10.1016/j.sbspro.2015.01.685

Benoit Rihoux, H. G. (2006). Inovative Comparative Methods for Policy Analysis.

Brown, M. (2018). The 2018 OpenupEd T rend R eport on MOOCs, (July).

China State Council, \& Foundation for Law and International Affairs. (2017). New Generation of Artificial Intelligence Development Plan, 1-28. Retrieved from https://flia.org/notice-state-council-issuing-newgeneration-artificial-intelligence-development-plan/

Gaffar, F. E. P. (2020). Implementasi Kebijakan.

Franco, Y. C. E., Nigmonova, D., \& Panichpathom, W. (2014). DeMOOCratization of Education?: Massive Open Online Courses ( MOOCs ) and the opportunities and challenges for developing countries. Graduate Institute of International and Development Studies, Geneva, Switzerland, 1-84.

Heyang, T., \& Martin, R. (2020). A reimagined world: international tertiary dance education in light of COVID-19. Research in Dance Education, O0(00), 1-15. https://doi.org/10.1080/14647893.2020.1780206

Holstein, S., \& Cohen, A. (2016). The Characteristics of Successful MOOCs in the Fields of Software, Science, and Management, According to Students' Perception. Interdisciplinary Journal of E-Skills and Lifelong Learning, 12, 247-266. https://doi.org/10.28945/3614

Murphy, M. P. A. (2020). COVID-19 and emergency eLearning: Consequences of the securitization of higher education for post-pandemic pedagogy. Contemporary Security Policy, 41(3), $492-505$. https://doi.org/10.1080/13523260.2020.1761749

Nagy, J., Oláh, J., Erdei, E., Máté, D., \& Popp, J. (2018). The role and impact of industry 4.0 and the internet of things on the business strategy of the value chain-the case of hungary. Sustainability (Switzerland), 10(10). https://doi.org/10.3390/su10103491

OECD. (2019). Artificial Intelligence in Society. Artificial Intelligence in Society. https://doi.org/10.1787/eedfee77en

Olazabalaga, M. I., Garrido, C. C., \& Ruiz, U. G. (2016). Research on MOOCs: Trends and methodologies. Porta Linguarum, (SI), 87-98.

OpenupEd. (2015). Definition of Massive Open Online Courses (MOOCs), (March), 1-5. Retrieved from https://www.openuped.eu/images/docs/Definition_Massive_Open_Online_Courses.pdf

Organisation for Economic Co-operation and Development. (2016). The Internet of Things. Seizing the Benefits and Addressing the Challenges. OECD Digital Economy Papers, (252), 1-57. https://doi.org/10.1787/20716826

Osuwa, A. A., Ekhoragbon, E. B., \& Fat, L. T. (2018). Application of artificial intelligence in Internet of Things. Proceedings - 9th International Conference on Computational Intelligence and Communication Networks, CICN 2017, 2018-Janua, 169-173. https://doi.org/10.1109/CICN.2017.8319379

Rojko, A. (2017). Industry 4.0 concept: Background and overview. International Journal of Interactive Mobile Technologies, 11(5), 77-90.

Sharfuddin, S. (2020). The world after Covid-19. Round Table, 109(3), $247-257$. https://doi.org/10.1080/00358533.2020.1760498

Van De Heyde, V., \& Siebrits, A. (2020). Digital laboratory report writing, assessment and feedback in the 21st century for an extended curriculum programme for physics. Research in Science and Technological Education, OO(00), 1-32. https://doi.org/10.1080/02635143.2020.1775571

Zheng, P., wang, H., Sang, Z., Zhong, R. Y., Liu, Y., Liu, C., ... Xu, X. (2018). Smart manufacturing systems for Industry 4.0: Conceptual framework, scenarios, and future perspectives. Frontiers of Mechanical Engineering, 13(2), 137-150. https://doi.org/10.1007/s11465-018-0499-5

Zhong, S.-H., Zhang, Q.-B., Li, Z.-P., \& Liu, Y. (2016). Motivations and Challenges in MOOCs with Eastern Insights. International Journal of Information and Education Technology, 6(12), 954-960. https://doi.org/10.7763/ijiet.2016.v6.824 